\title{
Evaluating the use of social media to conduct clinical performance reviews of advanced practice nursing students
}

\author{
Jason A. Gregg * Denise K. Gormley, Christine Colella, Suzanne Perraud \\ College of Nursing, University of Cincinnati, Cincinnati, United States
}

Received: May 17, 2015

DOI: $10.5430 /$ jnep.v5n10p86

\author{
Accepted: July 17, 2015 \\ Online Published: July 27, 2015 \\ URL: http://dx.doi.org/10.5430/jnep.v5n10p86
}

\begin{abstract}
Although nurse leaders have argued for years that faculty clinical observations of students should be direct, the feasibility of this in online nursing programs is a challenge. As such, one would expect that the development of technology-based methods which permit direct evaluation of students in real time from a distance should be well underway. If so, little has been done to investigate the impact of methods utilizing social media strategies to evaluate clinical work of Advanced Practice Registered Nurse students. The purpose of this quality improvement project was to evaluate advanced practice nursing student and clinical preceptor perceptions of the feasibility and benefit of a real time student clinical performance review utilizing social media strategies which incorporated live audio and video feed. The quantitative data supports the use of synchronous evaluation and lends support to the need and viability for a real-time evaluation of students which is perceived as beneficial and feasible to preceptor, student, and faculty.
\end{abstract}

Key Words: Social media, Clinical, Evaluation, Nursing

\section{INTRODUCTION}

Distance education has evolved significantly over the past century. Advances in technology have transformed distance education as we know it, replacing mailed delivery of course content, and pencil and paper evaluation of student learning with a great variety of online educational tools and methods associated with computerized technology. Furthermore, the internet has produced a wide range of ever changing content delivery models, including those present in social networking. ${ }^{[1]}$ In response to a call for nursing to develop innovative ways for educating future nurses, ${ }^{[2,3]}$ online programs which improve educational options for students continue to expand in nursing at both the undergraduate and graduate levels. ${ }^{[4]}$
Proponents of the distance learning option in nursing maintain these delivery methods help alleviate faculty shortages by providing attractive options for faculty who prefer to work from home. ${ }^{[2,3]}$ Other arguments cited by those who approve of these methods include improved access for students in remote locations, and an increasing market share of students who reside close to brick and mortar universities who value the flexibility of online education for any number of reasons. ${ }^{[2,3]}$ Finally, it has been said that distance education can result in better communication between faculty, students, and clinical preceptors, and can increase the ease of evaluation of student performance, clinical preceptor effectiveness and clinical site appropriateness. ${ }^{[3-5]}$ Those speaking out against States.

*Correspondence: Jason A. Gregg; Email: greggjn@UCMAIL.UC.EDU; Address: College of Nursing, University of Cincinnati, Cincinnati, United 
the offering of distance learning options for nursing argue that there is no replacement for direct observation of nursing students in the clinical setting by faculty due to a lack of evaluation consistency across clinical preceptors, coupled with their lack of training as an academic. ${ }^{[4,5]}$

Since the year 2000, when online distance education began in earnest, many professional organizations have vocalized their position towards this new educational option. Torn between a mission to educate the large number of advanced practice nurses needed to care for an aging population with increasingly complex health and diversity issues, and concerns related to a move away from the traditions inherent in clinical education of nurses, nurse leaders were provided with a trending topic for debate. One influential report of particular interest to distance educators in nursing is the Alliance for Nursing Accreditation Statement on Distance Education Policies, published by the American Association of Colleges of Nursing (AACN) in 2007 ${ }^{[6]}$ and endorsed by many, if not all of the predominant advanced practice professional organizations of that time. This report states that nursing education programs offered at a distance must be held to the same standards as programs provided in face-to-face formats. Importantly, the report states that distance educational programs must establish the means to provide for the development of crucial clinical competencies, and for the evaluation of outcomes of its students and graduates, including those related to role socialization. ${ }^{[6]}$ As such, consideration should be given to the use of real time social media strategies which have the ability to virtually place distance learning faculty at clinical sites similar to traditional face-to-face visits.

The National Organization of Nurse Practitioner Faculties (NONPF) was one of the groups that endorsed the 2007 Alliance for Nursing Accreditation report. In the Criteria for Evaluation of Nurse Practitioner Programs (National Task Force on Quality Nurse Practitioner Education) published by NONFP, ${ }^{[7]}$ it is clear that faculty supervision includes preceptor and student interaction and evaluation during clinical experiences. The National Task Force definition defines faculty oversight through such things as site visits, emails, and phone consultation. Furthermore, schools of nursing are to establish mechanisms that not only ensure learning objectives are met but also, as stated in the Alliance report, provide for the means to document student outcomes. ${ }^{[7]}$ This means that evaluations of students should be based on observations of, and interactions with, NP faculty and clinical preceptors. Since some nurse leaders have argued for years that those observations should be direct, one would expect that the development of technology to perform direct evaluation of students from a distance should be well underway. If so, little has been done to investigate the impact of these meth-

Published by Sciedu Press ods on faculty evaluation of student clinical performance review. ${ }^{[3-5]}$ The purpose of this quality improvement project was to evaluate advanced practice registered nursing (APRN) students and clinical preceptor perceptions of the feasibility and benefit of a real time student clinical performance review utilizing social media strategies which incorporated live audio and video feed.

\section{Methods}

This pilot project used a descriptive survey design for the purpose of evaluating student and preceptor perceptions related to the feasibility and benefits related to a synchronized APRN student clinical performance review. This project was determined not to be human subject research by the University of Cincinnati Institutional Review Board.

\subsection{Sampling}

As part of course requirements, APRN students enrolled in a Family Nurse Practitioner Distance Learning Practicum course at the University of Cincinnati during the summer of 2013 were required to complete a student performance evaluation through a technological platform which incorporated simultaneous audio and video feed between the student, clinical preceptor, and course faculty. Frank discussion related to student goals and performance of skills took place in these meetings. After completion of the synchronized reviews, students and preceptors were invited through email to voluntarily complete an anonymous survey through SurveyMonkeyß related to their perceptions of the evaluation method. Both students and preceptors were sent weekly email invitations

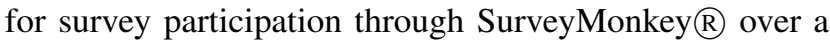
period of 3 weeks. Sixty-nine students (return rate of 75\%) and 73 preceptors (return rate of $79 \%$ ) completed the survey on perceptions of synchronized clinical review.

\subsection{Measures}

In order to satisfy the overall purpose of evaluating APRN student and clinical preceptor perceptions, items related to feasibility and benefits were assessed through Likert-scale items examining extent of perceived agreement in relation to the review method being feasible; extent of perceived agreement in relation to the review method being beneficial; extent of perceived agreement in relation to this type of review method being more advantageous than the traditional, written review; and their overall experience rating on a numerical score range. Attention was also give to demographic and social resources data: setting type of clinical practice rotation experience (i.e., Family, Pediatrics, etc.); time zone of clinical practice location; technology capabilities of the clinical practice including internet and Wi-Fi access; geographic description of the clinical practice location (i.e., rural, urban, 
etc.); and the type of social media communication utilized (i.e., FaceTime, Skype, etc.).

Data were collected via anonymous survey and included preceptor credentials, clinical placement site, technology capabilities of sites, communication tools used for evaluation, geographic description of clinical sites, and week of term for review. Students and preceptors were also asked to respond to several statements related to the benefits and feasibility of the synchronous remote clinical evaluation methods, and their overall experience with this method.

\section{RESUlts}

Sixty-nine students (return rate of $75 \%$ ) and 73 preceptors (return rate of $79 \%$ ) completed the survey on perceptions of synchronized clinical review. Of the preceptors who responded to the survey, $63 \%$ were APRNs, $29 \%$ were Medical Doctors (MD), and 8\% were Doctors of Osteopathic Medicine (DO). The APRN students were in a variety of settings for the clinical experience. See Table 1 for a description of clinical setting sites and number of students in each type of setting.

Table 1. Setting of clinical rotation experience at time of performance evaluation

\begin{tabular}{llllll}
\hline & Family Practice & Pediatrics & Women's Health & Acute Care (ER or UTC) & Specialty Practice \\
\hline Student & $42(61 \%)$ & $18(26 \%)$ & $6(9 \%)$ & $1(1 \%)$ & $2(3 \%)$ \\
Preceptor & $40(55 \%)$ & $14(19 \%)$ & $7(10 \%)$ & $8(11 \%)$ & $4(5 \%)$ \\
\hline
\end{tabular}

The geographic descriptions of the clinical practice sites at the time of the performance review were in rural, urban and suburban settings. Of the 69 students who participated in the survey, $21(31 \%)$ were in rural placements, $14(20 \%)$ were in urban settings, and 34 (49\%) completed the clinical evaluation while in a suburban clinical site. Students in the FNP distance learning program are enrolled from all across the United States. Table 2 displays the time zones of the clinical practice location for the preceptors and students who completed the survey.

Table 2. Time zone of clinical practice location at time of performance evaluation

\begin{tabular}{lllllll}
\hline & Atlantic Standard & Eastern Standard & Central Standard & Mountain Standard & Pacific Standard & Other \\
\hline Student & $0(0 \%)$ & $46(66.67 \%)$ & $12(17.39 \%)$ & $4(5.80 \%)$ & $5(7.25 \%)$ & $2(2.90 \%)$ \\
Preceptor & $0(0 \%)$ & $49(68.06 \%)$ & $15(20.83 \%)$ & $4(5.56 \%)$ & $3(4.17 \%)$ & $1(1.39 \%)$ \\
\hline
\end{tabular}

Evaluations of student progress in the practice site were completed using a variety of technological methods. Fifty-nine $(81 \%)$ of the preceptors reported that the clinical site had both internet access and Wi-Fi access. The remainder of the preceptors $(\mathrm{N}=14 ; 19 \%)$ reported that they had access to the internet but no Wi-Fi capabilities. Based on the internet or Wi-Fi access in the clinical site, clinical evaluations were conducted using Face Time (60\%), Tango (36\%) and Skype
(4\%). When asked in the survey if the synchronous remote method used for student clinical performance evaluation was beneficial, the majority of students and preceptors responded that they "Agree" or "Strongly Agree". See Table 3 for survey results related to the statement "I found this type of student performance review to be beneficial" with responses ranging from "Strongly Disagree", "Disagree", "Neither Disagree or Agree", "Agree", and "Strongly Agree".

Table 3. Extent of perceived benefits of synchronous remote student-preceptor clinical evaluation

\begin{tabular}{llllll}
\hline & Strongly Disagree & Disagree & Neither Disagree of Agree & Agree & Strongly Agree \\
\hline Student & $4(6 \%)$ & $5(7 \%)$ & $10(14 \%)$ & $30(44 \%)$ & $20(29 \%)$ \\
Preceptor & $2(3 \%)$ & $8(11 \%)$ & $10(14 \%)$ & $41(56 \%)$ & $12(16 \%)$ \\
\hline
\end{tabular}

Clinical preceptors and students were also asked to respond to the statement "I found this type of student performance review to be feasible" with the above possible responses. Again, the majority of preceptors and students responded that they "Agree" or "Strongly Agree" with the feasibility of the synchronous remote method of clinical evaluation. See Table 4 for preceptor and student responses. 
Table 4. Perception of feasibility of synchronous remote student-preceptor clinical evaluation

\begin{tabular}{llllll}
\hline & Strongly Disagree & Disagree & Neither Disagree of Agree & Agree & Strongly Agree \\
\hline Student & $2(3 \%)$ & $5(7 \%)$ & $8(12 \%)$ & $33(48 \%)$ & $21(30 \%)$ \\
Preceptor & $5(7 \%)$ & $5(7 \%)$ & $5(7 \%)$ & $40(55 \%)$ & $18(24 \%)$ \\
\hline
\end{tabular}

Preceptors and students were also asked to respond to the statement "I found this type of student performance review to be more advantageous than a traditional, written review" with the above potential responses. The majority of preceptors and students again responded with "Agree" or "Strongly Agree" to this statement. Table 5 displays the responses of preceptors and students to the statement.

As part of the review of this method of clinical evaluation, preceptors and students were also asked to rate their overall experience with the synchronous process of student clinical performance review on a scale of 0-10 with 0 being poor and 10 being excellent. Students rated this method of synchronous remote clinical evaluation with the mean score of 7.7. The median score for students was nine. Preceptors rated the synchronous method of evaluation similarly to the students with a mean score of 7.6 and a median score of eight.

Table 5. Perception of advantage of synchronous remote review over traditional written review

\begin{tabular}{llllll}
\hline & Strongly Disagree & Disagree & Neither Disagree of Agree & Agree & Strongly Agree \\
\hline Student & $6(9 \%)$ & $9(13 \%)$ & $14(20 \%)$ & $27(39 \%)$ & $13(19 \%)$ \\
Preceptor & $4(5.48 \%)$ & $9(12.33 \%)$ & $17(23.29 \%)$ & $25(34.25 \%)$ & $(24.66 \%)$ \\
\hline
\end{tabular}

\section{DISCUSSION}

Learning a practice profession at a distance has many challenges and a significant one is the interplay of preceptor and faculty. Capturing the precepted clinical data from a distance learning student is vital to any educational institution that offers this method of instruction. Knowing how the student is excelling in the clinical setting goes beyond paperwork and clinical log submissions; it requires a real-time dialogue. This pilot project gives insight to a method of evaluation that could meet the needs of the student, preceptor, and faculty.

The quantitative data supports the use of synchronous evaluation as beneficial to both the student and the preceptor. The preceptors found it to be better than written review. Often this type of evaluation is not considered because of the perceived difficulty in finding a time for the synchronous event to occur, but a majority of students and preceptors agreed or strongly agreed that it was feasible. This project supports to the real-time evaluation of students that is perceived as beneficial and feasible to preceptor, student, and faculty.

\section{Conclusion}

In lieu of standard online Likert-scale based evaluations completed about students by clinical preceptors, the University of Cincinnati Family Nurse Practitioner (FNP) Distance Learning Program piloted the use of social media to conduct student clinical performance reviews in real time between faculty, the clinical preceptor, and student. Overall, the data

Published by Sciedu Press supports the use of synchronous real time clinical evaluations as clinical preceptors and students in this pilot project found this method to be both beneficial and feasible, while also being preferred over written evaluation methods.

Implementation of these synchronized clinical performance reviews are not without challenges. Primary obstacles to implementation include: 1) trying to coordinate a synchronized review time between multiple parties in variable time zones during busy clinic hours; and 2) reduced cell telephone or internet signal reception strength needed to carry out use of the social media methods in some environments.

There are limitations of this pilot quality improvement project that need to be considered. First, the sample size of this pilot project was small and included only one APRN specialty program. Second, the survey evaluation tool of this pilot project did not utilize open-ended questions. Because of this, data results do not include identification of specific benefits and barriers for both students and preceptors, or include any issues related to dissatisfaction with the synchronized method of review or with the type of social media used. Future quality improvement projects should include other APRN specialty programs and the addition of open-ended questions.

Finally, this pilot project did not include direct observation of patient and student clinical interactions at the site due to ethical concerns related to patient privacy. Now that video recording programs have been developed that can be Health 


\section{Insurance Portability and Accountability Act (HIPAA) com- CONFLICTS OF INTEREST DISCLOSURE}

pliant, future projects should consider evaluation of direct The authors declare that there is no conflict of interest statepatient care activities at a distance with the student and pre- ment. ceptor.

\section{REFERENCES}

[1] Smith CE, Fontana-Chow K, Boateng BA, et al. Tele-education: Linking educators with learners via distance technology. Pediatric Annals. 2009; 38(10): 550-556. PMid:19968192 http://dx.doi .org/10.3928/00904481-20090918-10

[2] Rich KL, Nugent KE. A Unites States perspective on the challenges in nursing education. Nurse Education Today. 2010; 30: 228232. PMid:19932531 http://dx.doi.org/10.1016/j.nedt. 20 09.10 .015

[3] Grady J. The virtual clinical practicum: An innovative telehealth model for clinical nursing education. Nursing Education Perspectives. 2011; 32(3): 189-194. PMid:21834382 http://dx.doi.org/10. 5480/1536-5026-32.3.189
[4] Hoebeke R, MacLeod J. Faculty clinical site visits versus preceptor evaluation of NP students. The Journal for Nurse Practitioners. 2006; 2(5): 316-317. http://dx.doi.org/10.1016/j.nurpra. 2006 .03 .014

[5] McInnis LA, Wofford L. Should faculty make clinical site visits for students or rely on clinical preceptor evaluation. The Journal for Nurse Practitioners. 2006; 2(7): 448-449. http://dx .doi .org/1 $0.1016 / j$. nurpra. 2006.05.012

[6] Alliance for Nursing Accreditation. Statement on distance education policies. 2007.

[7] National Task Force on Quality Nurse Practitioner Education. Criteria for evaluation of nurse practitioner programs, 4th ed. Washington, DC: National Organization of Nurse Practitioner Faculties. 2012. 